Research Article

\title{
Evaluation and Analysis of a Method to Real-Name Check Train Tickets during the COVID-19 Pandemic
}

\author{
Jiao Yao $\mathbb{i}$, Qingyun Tang $(\mathbb{D}$, and Jiaping He $\mathbb{B}$ \\ Business School, University of Shanghai for Science and Technology, Shanghai 200093, China \\ Correspondence should be addressed to Jiao Yao; yaojiao@126.com
}

Received 10 March 2021; Accepted 17 July 2021; Published 29 July 2021

Academic Editor: Fabio Tramontana

Copyright ( 2021 Jiao Yao et al. This is an open access article distributed under the Creative Commons Attribution License, which permits unrestricted use, distribution, and reproduction in any medium, provided the original work is properly cited.

COVID-19 has swept the world for more than one year. Public transport, especially railway passenger transport for long distance and extensive areas, is the most potential risk source of the pandemic. In railway passenger transport, real-name train ticket check can effectively track the propagation path of the pandemic, which is of most significance for spread prevention of COVID-19. In this study, the evaluation index system of real-name check of ticket in trains was first established, in which 22 indexes in 4 levels were included, and their weights were determined by the Method of Kantiray Weighting. Furthermore, a comprehensive evaluation model of real-name system check was proposed, in which normalized work of different indexes was done, and key factors affecting the evaluation were founded. Finally, typical data of 8 trains check were collected, and from the evaluation analysis, we can find out that most factors affecting results of real-name ticket check are attendant management, train organization level, train service, and real-name ticket check proportion, based on which corresponding countermeasures and suggestions are given oriented to short-, medium-, and long-distance trains, respectively, all of which can reduce the risk of pandemic propagation in railway system.

\section{Introduction}

COVID-19 pandemic has swept the world for a long time. Railway passenger trains, as long-distance, extensive areas, and crowded places with public personnel, have become the most potential place of pandemic prevention and control. The motivation of this paper is to evaluate the real-name check of train ticket of railway to track the propagation path of the pandemic effectively.

With effective measures of pandemic prevention and control in the railway, traffic volume increase steadily. However, some potential issues of practical operation in real-name check of train ticket of railway may cause the propagation path of the pandemic, such as too short operation time between stations to finish the real-name check of train ticket and too much work for attendants of realname check, and sometimes they are even part time job for this work, which may decrease the efficiency, and some potential risks may be ignored, such as taking seats not according to the seat number of tickets, especially if there are available seats in high level class trains. All these are the challenge work for staff to carry out the real-name check of train ticket of railway, especially for tracking the propagation path of the pandemic with the passenger information, which are also challenges for evaluation of real-name check of train ticket of railway we will discuss in this paper.

The contributions of this paper are as follows:

(1) We proposed an evaluation index system of realname check of train ticket of railway, and Kantiray Weighting Method was taken to determine the weight of each index

(2) A comprehensive evaluation model of the real-name check was established, in which normalized work of different indexes was done, and key factors affecting the evaluation were found

(3) 8 trains of real-name check of train ticket were collected to verify the effectiveness of the model, and most factors affecting results of real-name check of train ticket of railway were found, based on which we 
give some specific corresponding countermeasures and suggestions

Because of COVID-19, measures have been taken all over China. They have had a negative impact on transportation. Jian [1] put forward four policy suggestions for the transportation industry under the pandemic situation. The suggestions include strengthening pandemic prevention in transportation, playing a role in transportation investment, increasing highway traffic service, and ensuring the transportation of key materials. Zhou and Jiang [2] compared the commonalities and differences between the COVID-19 pandemic and SARS pandemic, analyzed the impact of the COVID-19 pandemic on the development of passenger and cargo transportation in China, and predicted that the COVID-19 pandemic would in the short term have a large negative impact on railway. Huang et al. [3] considered transportation including waterway, when there were major infectious diseases. They created a management and emergency management system, when there is a pandemic. He et al. [4] used Baidu migration data to analyze the characteristics of intercity transportation during the COVID-19 pandemic. Using that data, they provided a quantitative decision-making basis for pandemic prevention and control. Ye et al. [5] proposed to make full use of large data sets to balance transportation with in-transit pandemic prevention and control. They provided diversified transportation services with the perceived demand to provide convenient travel. Zhou et al. [6] proposed that pandemic prevention strategies should be adjusted dynamically according to the current pandemic state. The passive defense should be combined with active prevention and control, and urban public transportation should play an active role in the pandemic period. Zhou [7] proposed that the emergence of the COVID-19 pandemic has had a great impact on road passenger transport, but the impact on highway infrastructure investment was relatively limited. Peng [8] pointed out that COVID-19 has caused a serious impact on the civil aviation market. The paper stated that civil aviation transportation in 2020 is not optimistic and that the annual passenger transportation volume is expected to be basically flat or decreased compared to the previous year. Based on the pandemic situation of COVID-19, Feng et al. [9-11] pointed out that a large number of passengers would appear in a short period of time after the outbreak. It stated that industry should be gradually strengthened so that it is orderly restored.

In the real-name system, the passenger's ID and ticket are checked when entering the waiting hall and at the train. In this paper, we only focus on trains to make sure the travelers' ID and ticket belong to the same person. Because most people wear masks during the COVID-19 pandemic, it is difficult for the conductor to verify the ticket holder from the photo id. When a conductor asks travelers to remove their mask to make identification easier, many feel uncomfortable. As a result, it is difficult for inspectors to make a correct identification.

The objective of paper is to evaluate the efficiency of ticket check work and to find the factors that will influence their efficiency.
For the real-name system check, scholars have carried out various studies, but the factors affecting the evaluation of the real-name system of train ticket during a pandemic need to be further clarified. Zhou et al. [12, 13] put forward a functional structure of a railway ticket system with real names to solve the problem of consistency between ticket and ID. It relieves the pressure of railway passenger transportation in order to improve the service level, because there is no correlation between traditional railway tickets and passengers. Yang [14] stated that the passenger transport contract between passengers and railway enterprises exists, and the railway cannot deal with the loss of real-name train tickets by passengers. Yao and Zhang [15] analyzed the main advantages and disadvantages of the current management methods of railway passenger tickets and put forward countermeasures for issues occurred in Checking Railway Electronic Tickets.

Because there are gaps in the above research, we randomly selected eight trains and categorized them whether they are short-, medium-, or long-distance trains. A method based on the invariant weight subconstraint model is proposed, and a comprehensive evaluation system for real-name check of train tickets during a pandemic was established.

Regarding the significance of this paper, this method provides a scientific basis for the management of the realname ticket check and creates an effective solution for the normal operation in a pandemic, which can reduce the risk of pandemic propagation in railway system.

\section{Materials and Methods}

As a crowded place, trains are a key factor in pandemic prevention and control. To ensure the smooth implementation for checking tickets, this paper can find out the key factors of the real-name system during a pandemic.

\subsection{Train Ticket Real-Name of Evaluation Index System.} According to the principles of availability, testability, and operability, the primary indicators must be selected to ensure that they are practical and quantifiable and can be supported by data. Twenty-two indicators were selected, and four criterion layers were set. Table 1 shows these criteria.

Based on the theory of subconstraint weight model and the Kantiray Weighting Method [16], this evaluation method decomposes the problem at multiple levels. The traditional method cannot explain the unreasonable phenomenon, in which the score of the "complete index system" is smaller than that of contribution removal of one or several indexes. To solve this problem, we will introduce the theory of constant weighting in the condition of secondary constraint. In this theory, we assume to remove contribution of one index, which means score 0 , and compare the score of other indexes before and after, so as to rank these indicators. Then, we can get the key factor, advantages and disadvantages factors affecting research object, which is Railway Electronic Tickets Checking in this paper. The model can extract the object of study by the key factors, advantage and disadvantage factors [17-23]. 
TABLE 1: Evaluation indexes for real-name check of tickets during pandemic.

\begin{tabular}{|c|c|c|c|}
\hline \multicolumn{2}{|c|}{ Criterion layer } & $\begin{array}{c}\text { Index name } \\
\text { No. of personnel }\end{array}$ & $\begin{array}{c}\text { Type } \\
\text { Positive }\end{array}$ \\
\hline Personnel management & Personnel information & $\begin{array}{c}\text { No. of personnel } \\
\text { Salary (salary/yuan) } \\
\text { Average age } \\
\text { Average train sections checked } \\
\text { Average of people per sections } \\
\text { Population (checks/hour) } \\
\text { Average check interval (time/hour) }\end{array}$ & $\begin{array}{l}\text { Positive } \\
\text { Positive } \\
\text { Positive } \\
\text { Moderate type } q=2 \\
\text { Forward direction } \\
\text { Positive } \\
\text { Positive }\end{array}$ \\
\hline Traffic organization level & & $\begin{array}{c}\text { Sections per train } \\
\text { Punctuality }(\%) \\
\text { Station dwell time/min } \\
\end{array}$ & $\begin{array}{l}\text { Moderate type } q=8 \\
\quad \text { Positive } \\
\text { Moderate type } q=2\end{array}$ \\
\hline Train service & & $\begin{array}{c}\text { Delay rate of interactive machine }(\%) \\
\text { Passengers with no face masks } \\
\text { Cooperation percentage }(\%) \\
\text { Proportion checked }\end{array}$ & $\begin{array}{l}\text { Negative } \\
\text { Negative } \\
\text { Positive } \\
\text { Positive }\end{array}$ \\
\hline Ratio of ID ticket checks & & $\begin{array}{c}\text { Proportion of IDs checked (\%) } \\
\text { Proportion of commuter staff (\%) } \\
\text { Proportion of temporary ID (\%) } \\
\text { Children tickets (\%) } \\
\text { Student tickets (\%) } \\
\text { No face and ID comparison check (\%) } \\
\text { No ticket and ID comparison check (\%) } \\
\text { Proportion of total ID check (\%) }\end{array}$ & $\begin{array}{l}\text { Positive } \\
\text { Negative } \\
\text { Negative } \\
\text { Negative } \\
\text { Negative } \\
\text { Negative } \\
\text { Negative } \\
\text { Positive }\end{array}$ \\
\hline
\end{tabular}

2.2. Weight Determination of the Evaluation Index. Weight design is an important component in the evaluation. The existing evaluation methods are the subjective weighting method, the objective weighting method, and the combination weighting method. The shortcomings of the subjective weighting method are that it only reflects the opinions of experts and often ignores the quantitative differences between indicators. The objective weighting method should consider the discrete degree of data, information content, and other characteristics. The combination weighting method has the difficulties of the other methods and is difficult to provide the criteria to determine the subjective and objective weight.

The method studied in this paper is an objective evaluation without subjective bias towards one index. The entropy weight method, the deviation maximization method, and Kantiray Weighting Method are given priority in [24]. Their advantage is that the introduction of the correlation coefficient matrix overcomes the disadvantages of the correlation between data. The introduction of standard deviation matrix solves the defects of factor analysis, in which data information is not enough.

The Kantiray Weighting Method is defined by the following steps:

(1) Calculate the correlation coefficient matrix B of the index. The correlation coefficient is defined in the following equation:

$$
b_{i k}=\frac{\sum_{j=1}^{n}\left(y_{i j}-\overline{y_{i}}\right)\left(y_{i j}-\overline{y_{k}}\right)}{\sqrt{\sum_{j=1}^{n}\left(y_{i j}-\overline{y_{i}}\right)^{2} \times} \sqrt{\sum_{j=1}^{n}\left(y_{k j}-\overline{y_{k}}\right)^{2}}} .
$$

In this equation, $y_{i j}$ and $y_{k j}$ represent the index $i$ and $k(1 \leq i, k \leq m)$ and $j j=(1, \ldots, n) ; \overline{y_{i}}$ and $\overline{y_{k}}$ are the average normalization scores of index $i$ and $k$; and $r_{i k}$ is the correlation coefficient of indexes $i$ and $k$. The correlation coefficient matrix $B$ can be obtained by placing the corresponding correlation coefficients into the matrix.

$$
B=\left[\begin{array}{ccccc}
b_{11} & b_{12} & b_{13} & \cdots & b_{1 m} \\
b_{21} & b_{22} & b_{23} & \cdots & b_{2 m} \\
b_{31} & b_{32} & b_{33} & \cdots & b_{3 m} \\
\vdots & \vdots & \vdots & \vdots & \vdots \\
b_{m 1} & b_{m 2} & b_{m 3} & \cdots & b_{m m}
\end{array}\right] .
$$

(2) Calculate the diagonal matrix $D$ of standard deviation. The equation of the standard deviation is as follows:

$$
p_{i}=\sqrt{\frac{\sum_{j=1}^{n}\left(y_{i j}-\bar{y}\right)^{2}}{n-1}} .
$$

In equation (3), $p_{i}$ is the standard deviation of the $i^{\text {th }}$ index, $y_{i j}$ is the value of the $i^{\text {th }}$ index in the $j^{\text {th }}$ evaluation object, $\bar{y}$ is the average value of the $i^{\text {th }}$ index, and $n$ is the total number of evaluation objects. The standard deviation matrix $S$ can be obtained placing these items in the diagonal of a matrix.

$$
D=\left[\begin{array}{cccc}
p_{1} & 0 & \cdots & 0 \\
0 & p_{2} & \cdots & 0 \\
\vdots & \vdots & & \vdots \\
0 & 0 & \cdots & p_{m}
\end{array}\right] .
$$


(4) Calculate the eigenvector corresponding to the maximum eigenvalue of matrix $B * D$. The equation is as follows:

$$
(B \times D) \times e=\lambda \times e .
$$

Equation (5) means that vector B is the eigenvector corresponding to the maximum eigenvalue of matrix $B * D$, which not only reflects the mutual influence among the indicators in the original data, but also reflects the variation of each indicator.

(5) Normalize the feature vectors to get the weight.

(6) Let $e=\left(e_{1}, e_{2}, e_{3}, \ldots, e_{i}, \ldots, e_{m}\right)$ normalize the eigenvector to get $e^{*}=\left(e_{1}^{*}, e_{2}^{*}, e_{3}^{*}, \ldots, e_{i}^{*}, \ldots, e_{m}^{*}\right)$, and the weight of the $i^{\text {th }}$ index $w_{i}$ is the absolute value of the $i^{\text {th }}$ component of $e^{*}$ as shown in the following equation:

$$
w_{i}=\left|e_{i}^{*}\right|=\left|\frac{e_{i}}{\sqrt{\sum_{i=1}^{m} e_{i}^{2}}}\right| .
$$

2.3. Comprehensive Evaluation Model of Train Ticket RealName System Check Effect. The data from all indicators are converted into the interval $[0,1]$ to eliminate the influence of the different data size. The normalization steps are as follows:
(1) Normalization of positive indicators:

$$
y_{i j}=\frac{c_{i j}-\min _{1 \leq j \leq n}\left(c_{i j}\right)}{\max _{1 \leq j \leq n}\left(c_{i j}\right)-\min _{1 \leq j \leq n}\left(c_{i j}\right)} .
$$

A positive index is when the higher the index value, the better the index, such as the "per capita realname system check personnel salary income."

(2) Normalization of negative indicators:

$$
y_{i, j}=\frac{\max _{1 \leq j \leq n}\left(c_{i j}\right)-c_{i, j}}{\max _{1 \leq j \leq n}\left(c_{i j}\right)-\min _{1 \leq j \leq n}\left(c_{i j}\right)} .
$$

Negative indicators are indicators that are better when the number is smaller, such as "the number of passengers not wearing masks, passenger dissatisfaction."

(3) Normalization of moderate indicators: a moderate index means that the closer the index value to a certain value, the better. For example, the ideal station dwell time is 2 minutes. A longer stop time will cause waste, and a shorter stop time will not be enough for boarding. During its normalization, a specific equation is selected depending on the size between the original value $c_{i j}$ and the optimal value $q$ as shown in the following equation:

$$
y_{i, j}= \begin{cases}1-\frac{q-c_{i j}}{\max \left(q-\min _{1 \leq j \leq n}\left(c_{i j}\right), \max _{1 \leq j \leq n}\left(c_{i j}\right)-q\right)}, & c_{i j}<q(a), \\ 1-\frac{c_{i j}-q}{\max \left(q-\min _{1 \leq j \leq n}\left(c_{i j}\right), \max _{1 \leq j \leq n}\left(c_{i j}\right)-q\right)}, & c_{i j}>q(b), \\ 1, & c_{i j}=q(c) .\end{cases}
$$

Equation (9) means that when the original value of the index $c_{i j}$ is equal to the optimal value of the index $q$, the normalization score is 1 . For instance, in the case when original value of the index $c_{i j}$ is greater than or less than $q$, the larger the gap, the lower the index.

The following evaluation model is established:

(1) Square the distance between the normalized score and the ideal value:

$$
d^{2}\left(y_{j}, y^{\alpha}\right)=\sum_{i=1}^{g}\left[w_{i}\left(y_{i j}-y_{i}^{\alpha}\right)\right]^{2} .
$$

Suppose that there are two vectors in the system, $y^{\alpha}$ and $y^{\beta}$ :

$$
\begin{aligned}
& y^{\alpha}=\left(y_{1}^{\alpha}, y_{2}^{\alpha}, \ldots, y_{g}^{\alpha}\right)^{T}=(1,1, \ldots, 1)^{T}, \\
& y^{\beta}=\left(y_{1}^{\beta}, y_{2}^{\beta}, \ldots, y_{g}^{\beta}\right)^{T}=(0,0, \ldots, 0)^{T} .
\end{aligned}
$$

In this equation, $y_{1}^{\alpha}, y_{2}^{\alpha}, \ldots, y_{q}^{\alpha}$ are the maximum normalization scores of the $i^{\text {th }}$ index; $y_{i}^{\beta}$ is the minimum normalization score of the $i^{\text {th }}$ index, 0 $(i=1,2, \ldots, g) ; y^{\alpha}$ is known as the "optimal vector"; $y^{\beta}$ is referred to as a "subvector".

After normalization, the values of each index are all between 0 and 1 , so the maximum and minimum scores of all indexes are all 1 and 0 .

(2) Square the distance between the normalization score of the evaluation object and the worst value: 


$$
d^{2}\left(y_{j}, y^{\beta}\right)=\sum_{i=1}^{g}\left[w_{i}\left(y_{i j}-y_{i}^{\beta}\right)\right]^{2} .
$$

Substitute the values of equations (10) and (12) into equation (13) to obtain the comprehensive evaluation scores.

$$
y_{j}^{\alpha}=\frac{1}{1+\left(d\left(y_{j}, y^{\alpha}\right) / d\left(y_{j}, y^{\beta}\right)\right)^{2}} .
$$

(3) Establish a model of key factors affecting the evaluation:

(a) Square the distance between an indicator score and the ideal value after normalization:

$$
d^{2}\left(y_{j}^{t_{k}}, y^{\alpha}\right)=\sum_{i=1}^{g}\left[w_{i}\left(y_{i j}^{t_{k}}-y_{i}^{\alpha}\right)\right]^{2} .
$$

(b) Square the distance from the worst value after normalization:

$$
d^{2}\left(y_{j}^{t_{k}}, y^{\beta}\right)=\sum_{i=1}^{g}\left[w_{i}\left(y_{i j}^{t_{k}}-y_{i}^{\beta}\right)\right]^{2} .
$$

(c) Substitute equations (14) and (15) into the following equation:

$$
\left(x_{j}^{\alpha}\right)^{t_{k}}=\frac{1}{1+\left(d\left(y_{j}^{t_{k}}, y^{\alpha}\right) / d\left(y_{j}^{t_{k}}, y^{\beta}\right)\right)^{2}} .
$$
$\left(x_{j}^{\alpha}\right)^{t_{k}}$ :

In equation (17), $\Delta\left(x_{j}^{\alpha}\right)^{t_{k}}$ is the difference of $x_{j}^{\alpha}$ and

$$
\Delta\left(x_{j}^{\alpha}\right)^{t_{k}}=x_{j}^{\alpha}-\left(x_{j}^{\alpha}\right)^{t_{k}} .
$$

In equation (17), $x_{j}^{\alpha}$ is the evaluation score based on the complete index system; $\left(x_{j}^{\alpha}\right)^{t_{k}}$ is the evaluation score of the remaining indicators after removing the contribution of the $k^{\text {th }}$ indicator. This equation represents the difference between the original and the modified score. The greater the change of the score, the greater its influence.

\section{Case Study Analysis}

3.1. Data Acquisition. This paper selected eight trains from the Shanghai Bureau, Jinan Bureau, and Nanchang Bureau, which are under the jurisdiction of the Shanghai Railway Supervision and Administration Bureau. These trains are two long-distance ones numbered $A 3$ (Shanghai HongqiaoQuanzhou) and $A 7$ (Shanghai Hongqiao-Tai'an), two middistance trains numbered $A 5$ (Fuzhou-Wuyuan) and $A 6$ (Shangrao-Shanghai Hongqiao), and four short-distance trains numbered $A 1$ (Wenzhou-Hangzhou East), A2 (Hangzhou East-Shanghai Hongqiao), A4 (South of Zhangzhou-Fuzhou), and $A 8$ (Tai" an-Linyi North). Because the short-distance trains have limited check time between stations, and the real-name system is labor intensive, there may be check errors. That is why the number of those trains was doubled. All of these data were collected at 2020. Considering intensive labor, to guarantee the accuracy, only 2 sections of each train data were collected. Each train has 2 inspectors, one for checking and one for verification.
The paper has accumulated sufficient data from the early stage of the pandemic and combined it with data before the pandemic controls. The data are shown in Table 2.

\subsection{Case Evaluation and Analysis}

\subsubsection{Index Normalization}

(1) Positive Indicator Normalization. A1 index "the number of real-name inspectors" is normalization. Since the number of inspectors is 1 , equation (7) $I=1$. The number of train real-name system checks is 8 , so $n=8$ in equation (7). Substitute the data from Table 2 into equation (7), and get the normalization score of A1 indicators "number of realname system inspectors" as follows:

$$
y_{11}=\frac{c_{11}-\min _{1 \leq j \leq 8}\left(c_{1 j}\right)}{\max _{1 \leq j \leq 8}\left(c_{i j}\right)-\min _{1 \leq j \leq 8}\left(c_{1 j}\right)}=\frac{3-2}{4-2}=0.5 .
$$

The score of 0.5 from equation (18) is listed in Table 3.

Similarly, the normalization of the number of real-name system check personnel for the other 7 trains is obtained and listed in Table 3. Similarly, the normalization scores of all the forward indicators of all the trains can be obtained and inserted in Table 3.

(2) Negative Indicator Normalization. In the indicator system, there are 8 negative indicators, such as "delay rate of interactive plane" and the number of passengers not wearing masks. For instance, the "delay rate of interactive plane" is numbered 11 , so $I=11$ in equation (8).

For the normalization of "interactive machine delay rate" of A1 train, one takes the data from Table 2 and inserts it into equation (8). One gets the following:

$$
y_{11,1}=\frac{\max _{1 \leq j \leq 8}\left(v_{11 j}\right)-v_{11,1}}{\max _{1 \leq j \leq 8}\left(v_{11 j}\right)-\min _{1 \leq j \leq 8}\left(v_{11 j}\right)}=\frac{0.2-0.1}{0.2-0}=0.5 \text {. }
$$

This score is listed in Table 3. Similarly, the normalization scores of negative indicators of other trains are obtained and listed in Table 3.

(3) Moderate Indicator Normalization. In the index system of this study, three indexes are moderate indexes. The fourth, eighth, and tenth lines of Table 2 are "the average number of trains inspected under real-name system," respectively, and the optimal value is 2. For "Number of train segments/ (segment)," the optimal value is 8 ; for "Inter-station running time/(min)," the optimal value is 2 .

Normalization of the "average number of trains inspected under the real-name system" of A1 train: since the index number of "average number of trains inspected under the real-name system" is $4, I=4$ in equation (9). The number of trains is 8 , so $n=8$ in equation (9). The optimal value of this index is 2 , so $q=2$. A1 "The average number of trains inspected under the real-name system is 4 , greater than $Q=2$, so equation (b) in equation (9) is selected as the normalization equation. 
TABle 2: Data from a train real-name system check under normal and pandemic conditions.

\begin{tabular}{|c|c|c|c|c|c|c|c|c|c|c|c|c|}
\hline No. & $\begin{array}{c}(1) \\
\text { Criterion layer }\end{array}$ & $(2)$ & $\begin{array}{c}(3) \\
\text { Index name }\end{array}$ & $\begin{array}{l}(4) \\
\text { type }\end{array}$ & $\begin{array}{l}(5) \\
A 1 \\
\end{array}$ & $\begin{array}{l}(6) \\
A 2\end{array}$ & $\begin{array}{l}(7) \\
A 3\end{array}$ & $\begin{array}{l}(8) \\
A 4\end{array}$ & $\begin{array}{l}(9) \\
A 5\end{array}$ & $\begin{array}{l}(10) \\
A 6\end{array}$ & $\begin{array}{l}(11) \\
A 7\end{array}$ & $\begin{array}{l}(12) \\
A 8\end{array}$ \\
\hline 1 & \multirow{7}{*}{$\begin{array}{c}\text { Personnel } \\
\text { management/hour }\end{array}$} & \multirow{7}{*}{$\begin{array}{l}\text { Personnel } \\
\text { information }\end{array}$} & Amount of personnel & Positive & 3 & 4 & 4 & 4 & 3 & 4 & 2 & 4 \\
\hline 2 & & & Average salary/yuan & Positive & 6500 & 5500 & 5600 & 4566 & 2555 & 6744 & 3456 & 5455 \\
\hline 3 & & & Average age & Positive & 26 & 24 & 23 & 23 & 24 & 24 & 25 & 26 \\
\hline 4 & & & $\begin{array}{l}\text { Average train sections } \\
\text { inspected }\end{array}$ & $\begin{array}{l}\text { Moderate } \\
\text { type } q=2\end{array}$ & 4 & 3 & 2 & 4 & 3 & 2 & 4 & 3 \\
\hline 5 & & & $\begin{array}{l}\text { Average of people per } \\
\text { sections }\end{array}$ & Positive & 70 & 48 & 95 & 93 & 25 & 52 & 95 & 75 \\
\hline 6 & & & Population check/hour & Positive & 149 & 358 & 115 & 248 & 69 & 111 & 170 & 374 \\
\hline 7 & & & $\begin{array}{l}\text { Average check interval } \\
\text { time (hour) }\end{array}$ & Positive & 6 & 3 & 2.5 & 3.5 & 3.2 & 2 & 2.2 & 3.4 \\
\hline 8 & \multirow{3}{*}{$\begin{array}{c}\text { Traffic organization } \\
\text { level }\end{array}$} & & Sections per train & $\begin{array}{l}\text { Moderate } \\
\text { type } q=8\end{array}$ & 8 & 6 & 6 & 16 & 8 & 17 & 16 & 8 \\
\hline 9 & & & Punctuality (\%) & Positive & 100 & 99.8 & 99.9 & 99.8 & 99.9 & 100 & 100 & 99 \\
\hline 10 & & & Station dwell time/min & $\begin{array}{l}\text { Moderate } \\
\text { type } q=2\end{array}$ & 2 & 1 & 2 & 1 & 1 & 3 & 2 & 3 \\
\hline 11 & \multirow{5}{*}{ Train service } & & $\begin{array}{l}\text { Delay rate of interactive } \\
\text { machine }(\%)\end{array}$ & Negative & 0.1 & 0.2 & 0.1 & 0 & 0 & 0.1 & 0 & 0.01 \\
\hline 12 & & & $\begin{array}{c}\text { Passengers with no face } \\
\text { masks }\end{array}$ & Negative & 2 & 4 & 2 & 1 & 3 & 1 & 2 & 3 \\
\hline 13 & & & $\begin{array}{c}\text { Cooperation percentage } \\
(\%)\end{array}$ & Positive & 98 & 97 & 99 & 98 & 99 & 99 & 97 & 98 \\
\hline 14 & & & Amount checked & Positive & 417 & 286 & 666 & 745 & 151 & 311 & 663 & 449 \\
\hline 15 & & & $\begin{array}{c}\text { Proportion of ID check } \\
(\%)\end{array}$ & Positive & 94 & 91.6 & 96.5 & 98.4 & 90 & 97.5 & 99.1 & 99.3 \\
\hline 16 & \multirow{7}{*}{$\begin{array}{l}\text { Ratio of ID ticket } \\
\text { checks }\end{array}$} & & $\begin{array}{c}\text { Proportion of } \\
\text { commuter staff }(\%)\end{array}$ & Negative & 3.4 & 0 & 0.5 & 0.1 & 2.6 & 0.6 & 0.2 & 0 \\
\hline 17 & & & $\begin{array}{c}\text { Proportion of } \\
\text { temporary ID (\%) }\end{array}$ & Negative & 0 & 0 & 0 & 0 & 2 & 0 & 0 & 0.2 \\
\hline 18 & & & Children tickets (\%) & Negative & 1.4 & 6.4 & 1.7 & 1.1 & 4 & 1.3 & 0.5 & 0 \\
\hline 19 & & & Student tickets (\%) & Negative & 1.2 & 1 & 0.1 & 0.4 & 0.7 & 0.6 & 0.3 & 0 \\
\hline 20 & & & $\begin{array}{l}\text { No face and ID } \\
\text { comparison check (\%) }\end{array}$ & Negative & 0 & 0.1 & 0.2 & 0.02 & 0.03 & 0 & 0.4 & 0.2 \\
\hline 21 & & & $\begin{array}{l}\text { No ticket and ID } \\
\text { comparison check (\%) }\end{array}$ & Negative & 0.2 & 0 & 0.2 & 0.2 & 0 & 0.3 & 0.2 & 0 \\
\hline 22 & & & $\begin{array}{c}\text { Proportion of total ID } \\
\text { check (\%) }\end{array}$ & Positive & 99.8 & 100 & 99.8 & 100 & 100 & 99.7 & 99.8 & 100 \\
\hline
\end{tabular}

TABLE 3: Normalization score $y_{i j}$ and corresponding weight $w_{i}$ of all indicators.

\begin{tabular}{|c|c|c|c|c|c|c|c|c|c|c|c|c|c|}
\hline No. & $\stackrel{(1)}{\text { Criterion layer }}$ & (2) & $\begin{array}{c}(3) \\
\text { Name of index }\end{array}$ & $\begin{array}{l}\text { (4) } \\
\text { Type }\end{array}$ & $\begin{array}{l}(5) \\
w_{i}\end{array}$ & $\begin{array}{l}(6) \\
A 1\end{array}$ & $\begin{array}{l}(7) \\
A 2\end{array}$ & $\begin{array}{l}(8) \\
A 3\end{array}$ & $\begin{array}{l}(9) \\
A 4\end{array}$ & $\begin{array}{l}(10) \\
A 5\end{array}$ & $\begin{array}{l}(11) \\
A 6\end{array}$ & $\begin{array}{l}(12) \\
A 7\end{array}$ & $\begin{array}{l}(13) \\
A 8\end{array}$ \\
\hline 1 & \multirow{7}{*}{$\begin{array}{c}\text { Personnel } \\
\text { management/h }\end{array}$} & \multirow{3}{*}{$\begin{array}{l}\text { Personnel } \\
\text { information }\end{array}$} & $\begin{array}{l}\text { Amount of } \\
\text { personnel }\end{array}$ & Positive & 0.080 & 0.500 & 1.000 & 1.000 & 1.000 & 0.500 & 1.000 & 0.000 & 1.000 \\
\hline 2 & & & $\begin{array}{l}\text { Average salary/ } \\
\text { yuan }\end{array}$ & Positive & 0.018 & 0.942 & 0.703 & 0.727 & 0.480 & 0.000 & 1.000 & 0.215 & 0.692 \\
\hline 3 & & & Average age & Positive & 0.043 & 1.000 & 0.333 & 0.000 & 0.000 & 0.333 & 0.333 & 0.667 & 1.000 \\
\hline 4 & & \multirow{4}{*}{$\begin{array}{l}\text { Labor } \\
\text { intensity }\end{array}$} & $\begin{array}{c}\text { Average train } \\
\text { sections inspected }\end{array}$ & $\begin{array}{l}\text { Moderate } \\
\text { type } q=2\end{array}$ & 0.089 & 0.000 & 0.500 & 1.000 & 0.000 & 0.500 & 1.000 & 0.000 & 0.500 \\
\hline 5 & & & $\begin{array}{l}\text { Average of people } \\
\text { per sections }\end{array}$ & Positive & 0.348 & 0.643 & 0.329 & 1.000 & 0.971 & 0.000 & 0.386 & 1.000 & 0.714 \\
\hline 6 & & & $\begin{array}{c}\text { Population check/ } \\
\text { hour }\end{array}$ & Positive & 0.002 & 0.262 & 0.948 & 0.151 & 0.587 & 0.000 & 0.138 & 0.331 & 1.000 \\
\hline 7 & & & $\begin{array}{c}\text { Average check } \\
\text { interval time/hour }\end{array}$ & Positive & 0.102 & 1.000 & 0.250 & 0.125 & 0.375 & 0.300 & 0.000 & 0.050 & 0.350 \\
\hline
\end{tabular}


TABLE 3: Continued.

\begin{tabular}{|c|c|c|c|c|c|c|c|c|c|c|c|c|c|}
\hline No. & $\stackrel{(1)}{\text { Criterion layer }}$ & (2) & Name of index & $\begin{array}{l}(4) \\
\text { Type }\end{array}$ & $\begin{array}{l}(5) \\
w_{i}\end{array}$ & $\begin{array}{l}(6) \\
A 1\end{array}$ & $\begin{array}{l}(7) \\
\text { A2 }\end{array}$ & $\begin{array}{l}(8) \\
A 3\end{array}$ & $\begin{array}{l}(9) \\
A 4\end{array}$ & $\begin{array}{l}(10) \\
A 5\end{array}$ & $\begin{array}{l}(11) \\
A 6\end{array}$ & $\begin{array}{l}(12) \\
A 7\end{array}$ & $\begin{array}{l}(13) \\
A 8\end{array}$ \\
\hline 8 & \multirow{3}{*}{$\begin{array}{c}\text { Traffic } \\
\text { organization } \\
\text { level }\end{array}$} & & Sections per train & $\begin{array}{l}\text { Moderate } \\
\text { type } q=8\end{array}$ & 0.284 & 1.000 & 0.780 & 0.780 & 0.110 & 1.000 & 1.000 & 0.110 & 1.000 \\
\hline 9 & & & Punctuality (\%) & Positive & 0.029 & 1.000 & 0.800 & 0.900 & 0.800 & 0.900 & 1.000 & 1.000 & 0.000 \\
\hline 10 & & & $\begin{array}{l}\text { Station dwell time/ } \\
\text { min }\end{array}$ & $\begin{array}{l}\text { Moderate } \\
\text { type } q=2\end{array}$ & 0.292 & 1.000 & 0.000 & 1.000 & 0.000 & 0.000 & 0.000 & 1.000 & 0.000 \\
\hline 11 & \multirow{4}{*}{ Train service } & & $\begin{array}{c}\text { Delay rate of } \\
\text { interactive machine } \\
(\%)\end{array}$ & Negative & 0.115 & 0.500 & 0.000 & 0.500 & 1.000 & 1.000 & 0.500 & 1.000 & 0.950 \\
\hline 12 & & & $\begin{array}{l}\text { Passengers with no } \\
\text { face masks }\end{array}$ & Negative & 0.227 & 0.667 & 0.000 & 0.667 & 1.000 & 0.333 & 1.000 & 0.667 & 0.333 \\
\hline 13 & & & $\begin{array}{c}\text { Cooperation } \\
\text { percentage }(\%)\end{array}$ & Positive & 0.108 & 0.500 & 0.000 & 1.000 & 0.500 & 1.000 & 1.000 & 0.000 & 0.500 \\
\hline 14 & & & Amount checked & Positive & 0.350 & 0.448 & 0.227 & 0.867 & 1.000 & 0.000 & 0.269 & 0.862 & 0.502 \\
\hline 15 & \multirow{8}{*}{$\begin{array}{l}\text { Ratio of ID } \\
\text { ticket checks }\end{array}$} & & $\begin{array}{c}\text { Proportion of ID } \\
\text { check (\%) }\end{array}$ & Positive & 0.346 & 0.430 & 0.172 & 0.699 & 0.903 & 0.000 & 0.807 & 0.979 & 1.000 \\
\hline 16 & & & $\begin{array}{c}\text { Proportion of } \\
\text { commuter staff (\%) }\end{array}$ & Negative & 0.215 & 0.000 & 1.000 & 0.853 & 0.971 & 0.235 & 0.824 & 0.941 & 1.000 \\
\hline 17 & & & $\begin{array}{c}\text { Proportion of } \\
\text { temporary ID (\%) }\end{array}$ & Negative & 0.280 & 1.000 & 0.000 & 0.000 & 0.000 & 1.000 & 0.000 & 0.000 & 0.100 \\
\hline 18 & & & $\begin{array}{c}\text { Children tickets } \\
(\%)\end{array}$ & Negative & 0.236 & 0.781 & 0.000 & 0.734 & 0.828 & 0.375 & 0.797 & 0.922 & 1.000 \\
\hline 19 & & & $\begin{array}{l}\text { Student tickets (\%) } \\
\text { No face and ID }\end{array}$ & Negative & 0.219 & 0.000 & 0.167 & 0.917 & 0.667 & 0.417 & 0.500 & 0.750 & 1.000 \\
\hline 20 & & & $\begin{array}{c}\text { comparison check } \\
(\%)\end{array}$ & Negative & 0.224 & 1.000 & 0.750 & 0.500 & 0.950 & 0.925 & 1.000 & 0.000 & 0.500 \\
\hline 21 & & & $\begin{array}{l}\text { No ticket and ID } \\
\text { comparison check } \\
(\%)\end{array}$ & Negative & 0.249 & 0.333 & 1.000 & 0.333 & 0.333 & 1.000 & 0.000 & 0.333 & 1.000 \\
\hline 22 & & & $\begin{array}{l}\text { Proportion of total } \\
\text { ID check (\%) }\end{array}$ & Positive & 0.160 & 0.333 & 1.000 & 0.333 & 1.000 & 1.000 & 0.000 & 0.333 & 1.000 \\
\hline
\end{tabular}

Substitute the data from columns 5 to 12 of row 4 in Table 2 into equation (b) of equation (9), and get the normalization score of $A 1$, which is the "average number of train segments in real-name system check":

$$
\begin{aligned}
y_{4,1} & =1-\frac{v_{4,1}-2}{\max \left(2-\min _{1 \leq j \leq 8}\left(v_{4 j}\right), \max _{1 \leq j \leq 8}\left(v_{4 j}\right)-2\right)} \\
& =1-\frac{4-2}{\max ((4-2),(4-4))}=1-\frac{2}{\max (2,0)}=0 .
\end{aligned}
$$

In the same way, the "average section number of trains inspected under the real-name system" of the trains in the case of all normal and pandemics can be obtained. For the number of train sections/(section), the normalization scores of the three moderate indexes of "inter-station running time/ (min)" are listed in Table 3.

\subsubsection{Determination of Index Weight}

(1) Calculate the Correlation Coefficient Matrix B of the Data. The correlation coefficient of the index "the number of realname inspectors" and "the average salary of real-name inspectors:" the numbers of the two indexes are 1 and 2, respectively, so $\mathrm{I}=1, k=2$ in equation (1). The number of trains is 8 , so $n=8$ in equation (1). Substitute the data from Table 3 into equation (1), and the correlation coefficient of the index "the number of real-name check personnel" and "the average salary of real-name check personnel" is obtained:

$$
b_{12}=\frac{\sum_{j=1}^{n}\left(y_{1 j}-\overline{y_{1}}\right)\left(y_{2 j}-\overline{y_{2}}\right)}{\sqrt{\sum_{j=1}^{n}\left(y_{1 j}-\overline{y_{1}}\right)^{2} \times \sqrt{\sum_{j=1}^{n}\left(y_{2 j}-\overline{y_{2}}\right)^{2}}}}=0.5017 .
$$

This correlation coefficient is placed in matrix $B$. The other indicators are similarly obtained.

All indicators were inserted into matrix B as follows:

$$
B=\left[\begin{array}{ccccc}
1 & 0.5017 & -0.4102 & \cdots & 0.2593 \\
0.5017 & 1 & 0.1716 & \cdots & -0.4637 \\
-0.4102 & 0.1716 & 1 & \cdots & -0.0594 \\
\vdots & \vdots & \vdots & \vdots & \vdots \\
0.2593 & -0.4637 & -0.0594 & \cdots & 1
\end{array}\right]
$$

(2) Calculate the Standard Deviation Matrix. The index number of "real-name check personnel" is 1 , so $n=8$ in equation (3), which means data of 8 trains were collected. 
Then, one substitutes the data from Table 3 into equation (3) to get the standard deviation of "the number of real-name system check personnel":

$$
p_{i}=\sqrt{\frac{\sum_{j=1}^{8}\left(y_{1 j}-\bar{y}\right)^{2}}{8-1}}=0.9728
$$

This number was included in matrix D. Similarly, the standard deviations of the indicators were obtained and included. The standard deviation matrix is

$$
D=\left[\begin{array}{cccc}
0.9728 & 0 & \cdots & 0 \\
0 & 0.9090 & \cdots & 0 \\
\vdots & \vdots & & \vdots \\
0 & 0 & \cdots & 1.0430
\end{array}\right] .
$$

(3) Calculate the Matrix $B * D$. By multiplying matrix B by $D$, one gets the following result:

$$
B \times D=\left[\begin{array}{cccc}
0.9728 & 0.4560 & \cdots & 0.2704 \\
0.4880 & 0.9090 & \cdots & -0.4837 \\
\vdots & \vdots & & \vdots \\
0.2523 & -0.4215 & \cdots & 1.0430
\end{array}\right] .
$$

(4) Calculate the Eigenvector Corresponding to the Maximum Eigenvalue of Matrix $B * D$. Substitute equation (25) into equation (5), and all that is left in equation (5) are $\lambda$ and $e$. According to these equations, the maximum eigenvalue is $\lambda=6.5658$ and the corresponding eigenvector is

$e=(-0.1038,0.0229,-0.055,-0.1148,0.4502, \ldots,-0.2064)^{T}$.

(5) Normalize the Eigenvector e to Get the Weights. One normalizes the eigenvector to get vector $e^{*}$ and then takes the absolute value of it to get the weight vector $e$.

$e=(0.080311,0.017718,0.042554,0.088822,0.348323, \ldots, 0.159693)^{T}$.

The first component of the index "the number of realname check personnel" is 0.080311 . Similarly, the weights of the other indicators can be found in Table 3 .

3.2.3. Train Real-Name System Check and Evaluation Effect. Equation (10) is used to calculate the square $d^{2}\left(y_{1}, y^{a}\right)$ of the distance between the A1 train and the ideal value. The indexes in equation (10) from left to right are total number of indicators, so $g=22 ; w_{i}$ is the weight of index $i$ in Column 5 of Table 3; $y_{i j}$ is the normalization score of the $i$ index for train $j$, and the serial number of train A1 is 1 , so $j=1$. As mentioned previously, each component of the ideal value equation (10) is 1 , so $y_{i}^{\alpha}=1$.

$$
d^{2}\left(y_{1}, y^{a}\right)=\sum_{i=1}^{22}\left[w_{i}\left(y_{i 1}-y_{i}^{\alpha}\right)\right]^{2}=0.331070 .
$$

Equation (12) is used to calculate the square, $d^{2}\left(y_{1}, y^{\beta}\right)$, of the distance between the A1 train and the worst value. The values of indexes in equation (12) from left to right are as follows: the total number of indicators is 22 , so $g=22 ; w_{i}$ is the weight of the $i^{\text {th }}$ index; $y_{i j}$ is the normalization score of the $i^{\text {th }}$ index of train $j$, and the serial number of train $A 1$ is 1 , so $j=1$. The data from Table 3 are substituted into equation (12). Then one has

$$
d^{2}\left(y_{1}, y^{\beta}\right)=\sum_{i=1}^{22}\left[w_{i}\left(y_{i 1}-y_{i}^{\beta}\right)\right]^{2}=0.479787
$$

By substituting the result from equation (28), 0.331070, and the result from equation (29), 0.479787, into equation (13), one obtains the evaluation scores of the A1 train.

$$
\begin{aligned}
x_{1}^{\alpha} & =\frac{1}{1+\left(d^{2}\left(y_{1}, y^{a}\right) / d^{2}\left(y_{1}, y^{\beta}\right)\right)} \\
& =\frac{1}{1+(0.33107 / 0.47978)}=0.5917
\end{aligned}
$$

In the same way, the evaluation scores of the other trains were calculated. These are listed in Table 4, where the higher the score, the better.

\subsubsection{Key Factors Affecting the Effect of Real-Name Check of} Train Ticket

(i) Calculate how the score changes for the A1 train after one index is changed to 0 .

Equation (14) is used to calculate the "number of real-name check personnel" of the $A 1$ train $\left(d^{2}\left(y_{1}^{t_{1}}, y^{\alpha}\right)\right)$. When the score of "Number of realname check personnel" is changed to 0 , the square distance is

$$
d^{2}\left(y_{1}^{t_{1}}, y^{a}\right)=\sum_{i=1}^{22}\left[w_{i}\left(y_{i 1}^{t_{1}}-y_{i}^{\alpha}\right)\right]^{2}=0.3359
$$

Equation (15) is used to calculate the square $d^{2}\left(y_{1}^{t_{1}}, y^{\beta}\right)$ of the distance between $\mathrm{A} 1$ train and the worst value after the normalization score of "the number of real-name check personnel" is changed to 0 . When the score of "Number of real-name check personnel" is changed to 0 , the square distance and the worst value are

$$
d^{2}\left(y_{1}^{t_{1}}, y^{\beta}\right)=\sum_{i=1}^{22}\left[w_{i}\left(y_{i 1}^{t_{1}}-y_{i}^{\beta}\right)\right]^{2}=0.4782 \text {. }
$$

Using the values of the above two equations, we can get the evaluation score $\left(x_{1}^{\alpha}\right)^{t_{1}}$ after removing the contribution of "the number of real-name check personnel". 
TABLE 4: Ranking of the eight trains.

\begin{tabular}{lcccccccc}
\hline Train number & $A 3$ & $A 8$ & $A 4$ & $A 7$ & $A 1$ & $A 6$ & $A 5$ & $A 2$ \\
\hline Evaluation scores from all indicators & 0.794 & 0.701 & 0.621 & 0.615 & 0.592 & 0.545 & 0.390 & 0.318 \\
Train ranking & 1 & 2 & 3 & 4 & 5 & 6 & 7 & 8 \\
\hline
\end{tabular}

$$
\begin{aligned}
\left(x_{1}^{\alpha}\right)^{t_{1}} & =\frac{1}{1+\left(d\left(y_{1}^{t_{1}}, y^{\alpha}\right) / d\left(y_{1}^{t_{1}}, y^{\beta}\right)\right)} \\
& =\frac{1}{1+(0.3359 / 0.4782)}=0.5874 .
\end{aligned}
$$

(ii) Calculate the change of the evaluation scores of $A 1$ train after removing the contribution of one index.

The evaluation score $x_{1}^{\alpha}=0.5917$ is listed in Table 4 . $\left(x_{1}^{\alpha}\right)^{t_{1}}=0.5874$ from equation (32) is put into equation (17) to obtain the change $\Delta\left(x_{1}^{\alpha}\right)^{t_{1}}$ of the evaluation score after removing the contribution of "the number of real-name check personnel".

$$
\Delta\left(x_{1}^{\alpha}\right)^{t_{1}}=0.5917-0.5874=0.004325 .
$$

Similarly, the changes in the evaluation scores of after removing the other indicators are obtained. These values are listed in Table 5. In the same way, we can get the changes for the other trains.

According to the standard of key factor extraction, select the top three indicators as the key factors. These factors for the A1 train are "train number/section (section)," "temporary id check ratio (\%)," and "check personnel not ticket card/check the proportion (\%)." These are listed in Table 6 . The ranking of the other trains is also listed in that table.

One key factor, which is common to many trains, is "ID card check proportion (\%)." This commonality indicates that it is important. Other key factors are unique to certain trains. For example, a key factor of the $A 3$ train is "running time between stations," which indicates that the organizational level of Nanchang Bureau is higher than the other. The key factors of Nanchang Bureau, Shanghai Bureau, and Jinan Bureau all include "average of people per sections." This indicates that real-name check rate from these bureaus depends on the labor of the check personnel. However, for $A 3$, this index is not the key factor. This result indicates that the labor intensity of personnel in not significant $[25,26]$.

3.2.5. Suggestions on Improving the Effect of Train Real-Name Check. Next, we study the effect of real-name ticket checking. We calculated what would happen when the variable "number of real-name system check personnel" is removed. The results are shown in Table 7.

For the extraction of the quality factors, the evaluation standard of the superior factors was that the variation of the scores before and after removing the contribution of one index ranked in the top 3 of all the trains. The evaluation criterion of the inferior factors is that the variation of the scores before and after removing the contribution of one index ranks the bottom 3 of all the trains. According to the ranking results in line 1 of Table 7, after removing the contribution of the index of "the system the number of check personnel," train A1 ranks $5^{\text {th }}$, not in the first 3 trains, nor in the last 3 trains, indicating that index "the system the number of check personnel" is neither train advantage factor, nor disadvantage factor of $A 1$. In the same way, we can get indexes in which train $A 1$ ranked in the first 3 trains (advantage factors) and last 3 trains (disadvantage factors), which are shown in Table 8 from line 2 to line 22. The ranking of changes in scores of dominant factors is listed in Table 8.

The $A 1$ trains have six disadvantages, which are listed in Table 9. The last column in that table has the change in the score when that disadvantage is removed. As the change is small for those disadvantages, these items are not very important.

The advantages and disadvantages of the trains are listed in Table 10, in which " $i$ " means train number. From the table, we can see that Shanghai Hongqiao-Quanzhou ranked the first with the most (12) advantages, while Taian-Linyi North ranked second with 15 . The middle-ranking trains are Shanghai Hongqiao-Tai'an and Wenzhou-Hangzhou East. Hangzhou East-Shanghai Hongqiao, which ranks the last, has 12 disadvantages. All these mean that key factors ranking have similarity with advantage and disadvantage factor numbers, but not full corresponding.

One needs to take account on both the advantages and disadvantages when evaluating a train. For example, train $A 7$ Shanghai Hongqiao-Tai'an has 8 advantages and 9 disadvantages, which leads to the lower check level than train $A 4$ South of Zhangzhou-Fuzhou. Based on the above analysis, the real-name verification levels are different for short- and medium-distance trains.

The long-distance category has disadvantage factors such as the average number of check staff strength. As the check level is relatively weak, there should be a higher number of check personal.

The short-distance category has several disadvantage factors such as the proportion of inspectors, number of cooperating of passengers, and ration between inspectors and tickets checked. All of these factors are affected by pandemic control. The data suggest that the railway should store the regulations into interactive machines and show them to passengers when appropriate. It could also have police accompanying the inspectors and have them deal with passengers who do not comply with the real-name system.

The medium-distance category has a disadvantage factor that includes the "proportion of commuter staff." This indicates that check is relatively lax for this category. For improvement, there should be better identification of employee commuters of train company, who take trains to work or home. 
TABLE 5: Change of evaluation score $\Delta\left(x_{j}^{\alpha}\right)^{t_{k}}$.

\begin{tabular}{|c|c|c|c|c|c|c|c|c|c|c|c|c|}
\hline No. & $\begin{array}{c}(1) \\
\text { Criterion layer }\end{array}$ & $(2)$ & $\begin{array}{c}(3) \\
\text { Name of index }\end{array}$ & $\begin{array}{l}\text { (4) } \\
\text { Type }\end{array}$ & $\begin{array}{l}(5) \\
\mathrm{A} 1\end{array}$ & $\begin{array}{l}(6) \\
\mathrm{A} 2\end{array}$ & $\begin{array}{l}(7) \\
\text { A3 }\end{array}$ & $\begin{array}{l}(8) \\
\mathrm{A} 4\end{array}$ & $\begin{array}{l}(9) \\
\text { A5 }\end{array}$ & $\begin{array}{c}(10) \\
\text { A6 }\end{array}$ & $\begin{array}{c}(11) \\
\text { A7 }\end{array}$ & $\begin{array}{l}(12) \\
\text { A8 }\end{array}$ \\
\hline 1 & \multirow{7}{*}{$\begin{array}{c}\text { Personnel } \\
\text { management/h }\end{array}$} & \multirow{4}{*}{$\begin{array}{l}\text { Personnel } \\
\text { information }\end{array}$} & Amount of personnel & Positive & 0.004 & 0.008 & 0.008 & 0.007 & 0.003 & 0.007 & 0.000 & 0.008 \\
\hline 2 & & & Average salary/yuan & Positive & 0.000 & 0.000 & 0.000 & 0.000 & 0.000 & 0.000 & 0.000 & 0.000 \\
\hline 3 & & & Average age & Positive & 0.002 & 0.001 & 0.000 & 0.000 & 0.001 & 0.001 & 0.001 & 0.002 \\
\hline 4 & & & $\begin{array}{l}\text { Average train sections } \\
\text { inspected }\end{array}$ & $\begin{array}{l}\text { Moderate } \\
\text { type } q=2\end{array}$ & 0.000 & 0.041 & 0.106 & 0.000 & 0.040 & 0.101 & 0.000 & 0.059 \\
\hline 5 & & \multirow[t]{3}{*}{ Labor intensity } & $\begin{array}{l}\text { Average of people per } \\
\text { sections }\end{array}$ & Positive & 0.096 & 0.034 & 0.144 & 0.123 & 0.000 & 0.053 & 0.129 & 0.107 \\
\hline 6 & & & Population check/h & Positive & 0.001 & 0.003 & 0.001 & 0.002 & 0.000 & 0.000 & 0.001 & 0.003 \\
\hline 7 & & & $\begin{array}{c}\text { Average check interval } \\
\text { time/h }\end{array}$ & Positive & 0.013 & 0.002 & 0.002 & 0.005 & 0.003 & 0.000 & 0.001 & 0.005 \\
\hline 8 & \multirow{3}{*}{$\begin{array}{c}\text { Traffic } \\
\text { organization level }\end{array}$} & & Sections per train & $\begin{array}{l}\text { Moderate } \\
\text { type } q=8\end{array}$ & 0.099 & 0.066 & 0.082 & 0.011 & 0.086 & 0.092 & 0.011 & 0.094 \\
\hline 9 & & & Punctuality (\%) & Positive & 0.001 & 0.001 & 0.001 & 0.001 & 0.001 & 0.001 & 0.001 & 0.000 \\
\hline 10 & & & Station dwell time/min & $\begin{array}{l}\text { Moderate } \\
\text { type } q=2\end{array}$ & 0.105 & 0.000 & 0.102 & 0.000 & 0.000 & 0.000 & 0.091 & 0.000 \\
\hline 11 & \multirow{4}{*}{ Train service } & & $\begin{array}{c}\text { Delay rate of } \\
\text { interactive machine } \\
(\%)\end{array}$ & Negative & 0.009 & 0.000 & 0.010 & 0.014 & 0.014 & 0.008 & 0.014 & 0.015 \\
\hline 12 & & & $\begin{array}{l}\text { Passengers with no } \\
\text { face masks }\end{array}$ & Negative & 0.044 & 0.000 & 0.048 & 0.054 & 0.015 & 0.059 & 0.039 & 0.025 \\
\hline 13 & & & $\begin{array}{c}\text { Cooperation } \\
\text { percentage }(\%)\end{array}$ & Positive & 0.008 & 0.000 & 0.014 & 0.007 & 0.013 & 0.013 & 0.000 & 0.008 \\
\hline 14 & & & Amount checked & Positive & 0.069 & 0.023 & 0.132 & 0.128 & 0.000 & 0.038 & 0.113 & 0.081 \\
\hline 15 & \multirow{8}{*}{$\begin{array}{c}\text { Ratio of ID ticket } \\
\text { checks }\end{array}$} & & $\begin{array}{c}\text { Proportion of ID check } \\
(\%)\end{array}$ & Positive & 0.065 & 0.016 & 0.111 & 0.113 & 0.000 & 0.107 & 0.125 & 0.140 \\
\hline 16 & & & $\begin{array}{c}\text { Proportion of } \\
\text { commuter staff }(\%)\end{array}$ & Negative & 0.000 & 0.055 & 0.050 & 0.047 & 0.010 & 0.043 & 0.047 & 0.054 \\
\hline 17 & & & $\begin{array}{c}\text { Proportion of } \\
\text { temporary ID (\%) }\end{array}$ & Negative & 0.097 & 0.000 & 0.000 & 0.000 & 0.084 & 0.000 & 0.000 & 0.012 \\
\hline 18 & & & Children tickets (\%) & & 0.055 & 0.000 & 0.055 & 0.049 & 0.019 & 0.051 & 0.055 & 0.065 \\
\hline 19 & & & Student tickets (\%) & Negative & 0.000 & 0.006 & 0.054 & 0.035 & 0.018 & 0.028 & 0.040 & 0.056 \\
\hline 20 & & & $\begin{array}{c}\text { No face and ID } \\
\text { comparison check (\%) }\end{array}$ & Negative & 0.062 & 0.040 & 0.038 & 0.050 & 0.048 & 0.057 & 0.000 & 0.034 \\
\hline 21 & & & $\begin{array}{l}\text { No ticket and ID } \\
\text { comparison check }(\%)\end{array}$ & Negative & 0.028 & 0.074 & 0.033 & 0.024 & 0.066 & 0.000 & 0.025 & 0.073 \\
\hline 22 & & & $\begin{array}{c}\text { Proportion of total ID } \\
\text { check (\%) }\end{array}$ & Positive & 0.012 & 0.030 & 0.014 & 0.027 & 0.027 & 0.000 & 0.010 & 0.030 \\
\hline
\end{tabular}

TABle 6: Top three key factors of the different trains.

\begin{tabular}{|c|c|c|c|c|}
\hline $\begin{array}{l}\text { Overall train } \\
\text { ranking }\end{array}$ & Train section & & Key factor & \\
\hline 1 & $\begin{array}{c}\text { A3 Shanghai Hongqiao- } \\
\text { Quanzhou }\end{array}$ & Sections per train & Station dwell time/min & $\begin{array}{c}\text { Proportion of temporary ID } \\
(\%)\end{array}$ \\
\hline 2 & A8 Tai'an-Linyi North & Sections per train & $\begin{array}{c}\text { Proportion of commuter } \\
\text { staff }(\%)\end{array}$ & $\begin{array}{c}\text { No ticket and ID comparison } \\
\text { check }(\%)\end{array}$ \\
\hline 3 & $\begin{array}{c}A 4 \text { south of Zhangzhou- } \\
\text { Fuzhou }\end{array}$ & $\begin{array}{l}\text { Average of people per } \\
\text { sections }\end{array}$ & Amount checked & Proportion of ID check (\%) \\
\hline 4 & A7 Shanghai Hongqiao-Tai'an & $\begin{array}{l}\text { Average of people per } \\
\text { sections }\end{array}$ & Amount checked & Proportion of ID check (\%) \\
\hline 5 & A1 Wenzhou-Hangzhou East & Sections per train & $\begin{array}{c}\text { Proportion of temporary } \\
\text { ID }(\%)\end{array}$ & $\begin{array}{c}\text { No ticket and ID comparison } \\
\text { check (\%) }\end{array}$ \\
\hline 6 & $\begin{array}{c}\text { A6 Shangrao-Shanghai } \\
\text { Hongqiao }\end{array}$ & $\begin{array}{l}\text { Average train sections } \\
\text { inspected }\end{array}$ & Sections per train & Proportion of ID check (\%) \\
\hline 7 & A5 Fuzhou-Wuyuan & $\begin{array}{l}\text { Average of people per } \\
\text { sections }\end{array}$ & Amount checked & Proportion of ID check (\%) \\
\hline 8 & $\begin{array}{c}\text { A2 Hangzhou East-shanghai } \\
\text { Hongqiao }\end{array}$ & $\begin{array}{c}\text { Average of people per } \\
\text { sections }\end{array}$ & Sections per train & Proportion of ID check (\%) \\
\hline
\end{tabular}


TABLE 7: Change of the evaluation score when the "number of real-name system check personnel" removed.

\begin{tabular}{|c|c|c|c|c|c|c|c|c|c|c|c|c|}
\hline No. & $\begin{array}{c}(1) \\
\text { Criterion layer }\end{array}$ & $(2)$ & $\begin{array}{c}(3) \\
\text { Name of index }\end{array}$ & $\begin{array}{l}\text { (4) } \\
\text { Type }\end{array}$ & $\begin{array}{l}(5) \\
A 1\end{array}$ & $\begin{array}{l}(6) \\
A 2 \\
\end{array}$ & $\begin{array}{l}(7) \\
A 3\end{array}$ & $\begin{array}{l}(8) \\
A 4 \\
\end{array}$ & $\begin{array}{l}(9) \\
A 5\end{array}$ & $\begin{array}{l}(10) \\
A 6\end{array}$ & $\begin{array}{l}(11) \\
A 7\end{array}$ & $\begin{array}{l}(12) \\
A 8\end{array}$ \\
\hline 1 & \multirow{7}{*}{$\begin{array}{c}\text { Personnel } \\
\text { management/hour }\end{array}$} & \multirow{3}{*}{$\begin{array}{l}\text { Personnel } \\
\text { information }\end{array}$} & Amount of personnel & Positive & 5 & 2 & 1 & 4 & 6 & 3 & 7 & 2 \\
\hline 2 & & & Average salary/yuan & Positive & 1 & 5 & 3 & 5 & 8 & 1 & 7 & 3 \\
\hline 3 & & & Average age & Positive & 1 & 6 & 7 & 7 & 5 & 4 & 3 & 2 \\
\hline 4 & & \multirow{4}{*}{ Labor intensity } & $\begin{array}{l}\text { Average train sections } \\
\text { inspected }\end{array}$ & $\begin{array}{l}\text { Moderate type } \\
\quad q=2\end{array}$ & 6 & 4 & 1 & 6 & 5 & 2 & 6 & 3 \\
\hline 5 & & & $\begin{array}{l}\text { Average of people per } \\
\text { sections }\end{array}$ & Positive & 5 & 7 & 1 & 3 & 8 & 6 & 2 & 4 \\
\hline 6 & & & Population check/hour & Positive & 5 & 2 & 6 & 3 & 8 & 7 & 4 & 1 \\
\hline 7 & & & $\begin{array}{c}\text { Average check interval time/ } \\
\text { hour }\end{array}$ & Positive & 1 & 6 & 5 & 3 & 4 & 8 & 7 & 2 \\
\hline 8 & \multirow{3}{*}{\multicolumn{2}{|c|}{ Traffic organization level }} & Sections per train & $\begin{array}{l}\text { Moderate type } \\
\quad q=8\end{array}$ & 1 & 6 & 5 & 8 & 4 & 3 & 7 & 2 \\
\hline 9 & & & Punctuality (\%) & Positive & 1 & 6 & 2 & 6 & 5 & 2 & 2 & 8 \\
\hline 10 & & & Station dwell time/min & $\begin{array}{l}\text { Moderate type } \\
q=2\end{array}$ & 1 & 4 & 2 & 4 & 4 & 4 & 3 & 4 \\
\hline 11 & \multirow{4}{*}{\multicolumn{2}{|c|}{ Train service }} & $\begin{array}{l}\text { Delay rate of interactive } \\
\text { machine }(\%)\end{array}$ & Negative & 6 & 8 & 5 & 4 & 3 & 7 & 2 & 1 \\
\hline 12 & & & $\begin{array}{c}\text { Passengers with no face } \\
\text { masks }\end{array}$ & Negative & 4 & 8 & 3 & 2 & 7 & 1 & 5 & 6 \\
\hline 13 & & & Cooperation percentage (\%) & Positive & 5 & 7 & 1 & 6 & 3 & 2 & 7 & 4 \\
\hline 14 & & & Amount checked & Positive & 5 & 7 & 1 & 2 & 8 & 6 & 3 & 4 \\
\hline 15 & \multirow{8}{*}{\multicolumn{2}{|c|}{ Ratio of ID ticket checks }} & Proportion of ID check (\%) & Positive & 6 & 7 & 4 & 3 & 8 & 5 & 2 & 1 \\
\hline 16 & & & $\begin{array}{c}\text { Proportion of commuter staff } \\
\qquad(\%)\end{array}$ & Negative & 8 & 1 & 3 & 4 & 7 & 6 & 5 & 2 \\
\hline 17 & & & $\begin{array}{c}\text { Proportion of temporary ID } \\
(\%)\end{array}$ & Negative & 1 & 4 & 4 & 4 & 2 & 4 & 4 & 3 \\
\hline 18 & & & Children tickets (\%) & Negative & 2 & 8 & 2 & 6 & 5 & 7 & 2 & 1 \\
\hline 19 & & & Student tickets (\%) & Negative & 8 & 7 & 2 & 4 & 6 & 5 & 3 & 1 \\
\hline 20 & & & $\begin{array}{c}\text { No face and ID comparison } \\
\text { check }(\%)\end{array}$ & Negative & 1 & 5 & 6 & 3 & 4 & 2 & 8 & 7 \\
\hline 21 & & & $\begin{array}{l}\text { No ticket and ID comparison } \\
\text { check (\%) }\end{array}$ & Negative & 5 & 1 & 4 & 7 & 3 & 8 & 6 & 2 \\
\hline 22 & & & $\begin{array}{c}\text { Proportion of total ID check } \\
(\%)\end{array}$ & Positive & 6 & 2 & 5 & 3 & 3 & 8 & 7 & 1 \\
\hline
\end{tabular}

TABLE 8: Advantages of real-name ticketing for the A1 train.

\begin{tabular}{lcc}
\hline Serial number & Advantage factors of Wenzhou-Hangzhou East $(A 1)$ & Sort of score change \\
\hline 1 & Average salary/yuan & 1 \\
2 & Average age & 1 \\
3 & Average check interval time/h & 1 \\
4 & Sections per train & 1 \\
5 & Punctuality (\%) & 1 \\
6 & Interstation running time/min & 1 \\
7 & Proportion of temporary ID (\%) & 1 \\
8 & No face and ID comparison check (\%) & 1 \\
9 & Children tickets (\%) & 2 \\
\hline
\end{tabular}

TABLE 9: Disadvantages of ticket real-name system for the $A 1$ train.

\begin{tabular}{lcc}
\hline Serial number & The disadvantage factor of Wenzhou-Hangzhou East (1) & Sort of score change \\
\hline 1 & Average train sections inspected & 6 \\
2 & Delay rate of interactive machine (\%) & 6 \\
3 & Proportion of ID check (\%) & 6 \\
4 & Proportion of total ID check (\%) & 6 \\
5 & Proportion of commuter staff (\%) & 8 \\
6 & Student ticket (\%) & 8 \\
\hline
\end{tabular}


TABLE 10: Advantages and disadvantages of real-name ticketing.

\begin{tabular}{|c|c|c|c|c|}
\hline \multicolumn{2}{|c|}{ Criterion layer } & Name of index & Virtue & Disadvantage \\
\hline Personnel management & Personnel information & $\begin{array}{c}\text { Amount of personnel } \\
\text { Average salary/yuan } \\
\text { Average age } \\
\text { Average train sections inspected } \\
\text { Average of people per sections } \\
\text { Population check } / \mathrm{h} \\
\text { Average check interval time/h }\end{array}$ & $\begin{array}{l}V 3, V 8, V 6, V 2 \\
V 3, V 8, V 1, V 6 \\
V 8, V 7, V 1 \\
V 3, V 8, V 7, V 6 \\
V 3, V 8, V 4 \\
V 4, V 2 \\
V 3, V 8, V 4, V 1\end{array}$ & $\begin{array}{c}D 7, D 5 \\
D 7 \\
D 3, D 4, D 5, D 2 \\
D 4, D 7, D 1 \\
D 6, D 5, D 2 \\
D 3, D 6, D 5 \\
D 7, D 6, D 2\end{array}$ \\
\hline Traffic organization level & & $\begin{array}{c}\text { Sections per train } \\
\text { Punctuality }(\%) \\
\text { Station dwell time/min }\end{array}$ & $\begin{array}{l}V 8, V 1, V 6 \\
V 3, V 7, V 1, V 6 \\
V 7, V 1\end{array}$ & $\begin{array}{l}D 4, D 7, D 2 \\
D 8, D 4, D 2\end{array}$ \\
\hline Train service & & $\begin{array}{c}\text { Delay rate of interactive machine }(\%) \\
\text { Passengers with no face masks } \\
\text { Cooperation percentage }(\%) \\
\text { Amount checked }\end{array}$ & $\begin{array}{l}V 8, V 7, V 5 \\
V 3, V 4, V 6 \\
V 3, V 6, V 5 \\
V 3, V 4\end{array}$ & $\begin{array}{c}D 1, D 2 \\
D 8, D 5, D 2 \\
D 4, D 7, D 2 \\
D 6, D 5, D 2\end{array}$ \\
\hline Ratio of ID ticket checks & & $\begin{array}{c}\text { Proportion of ID check (\%) } \\
\text { Percentage of commuter staff (\%) } \\
\text { Proportion of temporary ID (\%) } \\
\text { Children tickets (\%) } \\
\text { Student tickets (\%) } \\
\text { No face and ID comparison check (\%) } \\
\text { No ticket and ID comparison check (\%) } \\
\text { Percentage of total ID check (\%) }\end{array}$ & $\begin{array}{c}V 8, V 4, V 7 \\
V 3, V 8, V 2 \\
V 8, V 1, V 5 \\
V 3, V 8, V 7, V 1 \\
V 3, V 8, V 7 \\
\quad V 4, V 1 \\
V 8, V 6, V 5, V 2 \\
V 8, V 4, V 5, V 2\end{array}$ & $\begin{array}{l}D 1, D 5, D 2 \\
D 1, D 6, D 5 \\
\\
D 6, D 2 \\
D 1, D 5, D 2 \\
\text { D8 } \\
D 3, D 4, D 6 \\
D 1, D 6\end{array}$ \\
\hline
\end{tabular}

The disadvantages of short- and medium-distance trains include "the number of passengers not wearing masks", which indicates that these passengers have low pandemic safety awareness. These trains need to enhance the safety education of the passengers.

\section{Conclusions}

It has been concerns that measures to control COVID-19, can affect the implementation of the railway real-name check of train ticket of railways in China. To study the influence of the COVID-19 on real name check of train ticket, we have made several studies. The following is a summary of our results:

(1) In this study, we first established an evaluation index system of real-name check of train ticket, and the weight of each index was determined based on the Kantiray Weighting Method. Moreover, the comprehensive evaluation model of real-name check was given, in which the invariant weight subconstraint method was used, and finally key factors affecting effort of real-name check of train ticket were found out, and then relevant suggestions were put forward finally.

(2) Oriented to the long-, medium-, and short-distance trains, we put forward some countermeasures and suggestions, respectively:

(i) For long-distance trains, due to long interval between stations, and extensive working intensity of the train attendant, if difficult for them to finish the real-name check of train ticket in every station efficiently, so it is suggested that, during rush hour of passengers such as high class station arrival and departure, more attendants for real-name check of ticket in trains should be configured, and some flexible attendants can be considered to be in trains in cases.

(ii) For medium-distance trains, "proportion of commuter staff of railway company" is prominent, so it is suggested to strengthen the realname ID check certificate of commuter employee.

(iii) Compared with the other two kinds of trains, short-distance trains generally have most commuter staff and shortest operation time between stations. So, attendants in trains usually choose sampling check, which may increase the probability of ticket evasion of passenger. So, it is suggested that full time real-name check attendants for passengers with special type ticket should be arranged, and the number of real-name check attendants should be adjusted flexibly according to passenger flow demand of trains.

However, case study work has been finished in the area covered by Shanghai railway administration, which includes provinces of Shanghai, Jiangsu, Zhejiang, Anhui, Jiangxi, and Shandong, in which check stations for evaluation have obvious characteristics as follows: high density of train lines in network and somewhat bus operation, which has short operation time between stations, and short intervals between trains. For other areas of the country, the evaluation index and model may be modified according to local practical operation characteristics and conditions, so more flexible evaluation index system and model of real-name check of train tickets should be considered, which is also the work we should focus on in the future. 


\section{Data Availability}

The data used to support the findings of this study are included within the article (see Table 2 in the article).

\section{Conflicts of Interest}

The authors declare that they have no conflicts of interest.

\section{Acknowledgments}

This work was funded by Shanghai Philosophy and Social Science Project (Grant number: 2020BGL013). The authors, therefore, acknowledge with thanks the financial support of Shanghai Planning Office of Philosophy and Social Science. The authors would like to express their gratitude to EditSprings (https://www.editsprings.com/) for the expert linguistic services provided.

\section{References}

[1] J. Zhou, "Impact of COVID-19 pandemic on transportation industry and policy recommendations," Transportation Research, vol. 6, no. 1, pp. 13-18, 2020.

[2] Y. M. Zhou and C. L. Jiang, "Comparison and analysis of the influence of SARS and COVID-19 pandemic on passenger and freight transportation in China," Transportation Research, vol. 6, no. 1, pp. 24-32, 2020.

[3] C. Huang, Z. P. Wang, and W. Zhimou, "Research on emergency management system of waterway transportation safety under normal pandemic prevention and control," Traffic Information and Safety, vol. 38, no. 2, pp. $162-171+178,2020$.

[4] L. H. He, Q. Yu, W. F. Li et al., "Analysis of intercity transportation demand under the influence of COVID-19 pandemic situation," Urban Transport, vol. 18, no. 3, pp. 5161, 2020.

[5] J. H. Ye, Y. Liang, Y. F. Zhang et al., "Retrospectively analysis of COVID-19 pandemic situation in public health emergencies," Urban Transportation, vol. 18, no. 3, pp. 71-79, 2020.

[6] J. B. Zhou, C. X. Ma, S. Dong et al., "Unconventional pandemic prevention strategies of urban public transportation under the COVID-19 pandemic situation: a case study of Ningbo," China Journal of Highway and Transport, vol. 33, no. 11, pp. 1-10, 2020.

[7] G. G. Zhou, "Study on the impact of COVID-19 pandemic prevention and control on transportation industry and its measures," Transportation Finance \& Accounting, vol. 392, no. 3, pp. 4-7+12, 2020.

[8] Z. Peng, "Analysis and policy recommendations on the impact of COVID-19 pandemic on civil aviation," Journal of Transportation Research, vol. 6, no. 1, pp. 33-44, 2020.

[9] X. J. Feng, Y. Wang, S. H. Liu et al., "Impact of COVID-19 pandemic on urban rail transit operation," Transportation Research, vol. 6, no. 1, pp. 45-49, 2020.

[10] G. P. Zhang, H. C. Li, G. Xiao et al., "Thoughts and suggestions on China's emergency transportation system under the COVID-19 pandemic," Transportation Research, vol. 6, no. 1, pp. 81-88, 2020.

[11] Z. J. Zhou, S. Liu, and L. Zhang, "A review of the epidemiological and epidemiological implications of the COVID-19 pandemic in China," Transportation Research, vol. 6, no. 1, pp. 89-96, 2020.
[12] Q. Zhou, Z. Q. Zhang, S. D. Li, and N. Wu, "Design and realization of real-name registration rules in railway ticketing system," Railway Transportation and Economy, vol. 41, no. 7, pp. 54-59, 2019.

[13] S. S. Yang, Research on the Design and Application of Management Information System of Real Name System of Labor Service in Ji-Qing High-Speed Railway, Southwest Jiaotong University, Chengdu, China, 2018.

[14] B. G. Yang, "Analysis of the legal nature of real-name train tickets and the legal consequences of lost tickets," Law and Society, vol. 12, no. 3, pp. 64-65, 2017.

[15] J. Yao and K. M. Zhang, "Research on the current situation, problems and countermeasures of railway passenger ticket real-name system," Logistics Science and Technology, vol. 40, no. 9, pp. 71-76, 2017.

[16] M. Shwartz Jr, J. F. Burgess, and J. Zhu, "A DEA based composite measure of quality and its associated data uncertainty interval for health care provider profiling and pay-forperformance," European Journal of Operational Research, vol. 253, no. 2, pp. 489-502, 2016.

[17] B. Eder, J. Bash, K. Foley, and J. Pleim, "Incorporating principal component analysis into air quality model evaluation," Atmospheric Environment, vol. 82, no. 1, pp. 307-315, 2014.

[18] Z. Zhang and S. Liu, "Coupled principal component analysis based face recognition in heterogeneous sensor networks," Signal Processing, vol. 126, no. 9, pp. 134-140, 2016.

[19] P. Sun, "The application of factor analysis in the study on cultural industry competitiveness evaluation index system," Advanced Materials Research, vol. 989-994, no. 3, pp. 5132$5135,2014$.

[20] N. Jafari and A. H. Pourjohari, "Economic value creation in metro complexes: case study on sadr station complex in tehran," Journal of History Culture and Art Research, vol. 6, no. 2, pp. 678-689, 2017.

[21] B. Zhao, T. Tang, and B. Ning, "System dynamics approach for modelling the variation of organizational factors for risk control in automatic metro," Safety Science, vol. 94, no. 4, pp. 128-142, 2017.

[22] Z. Z. Wang and C. Chen, "Fuzzy comprehensive Bayesian network-based safety risk assessment for metro construction projects," Tunnelling and Underground Space Technology, vol. 70, no. 11, pp. 330-342, 2017.

[23] N. Aydin, "A fuzzy-based multi-dimensional and multi-period service quality evaluation outline for rail transit systems," Transport Policy, vol. 55, no. 4, pp. 87-98, 2017.

[24] H. Ma, "Objective weighting method in comprehensive evaluation system," Cooperative Economy \& Science \& Technology, vol. 16, no. 17, pp. 50-51, 2009.

[25] L. Gao, Y. Zheng, Y. Ji, C. Fu, and L. Zhang, "Reliability analysis of bus timetabling strategy during the COVID-19 epidemic: a case study of yixing, China," Discrete Dynamics in Nature and Society, vol. 2021, Article ID 6688236, 14 pages, 2021.

[26] B. Qi, H. Peng, K. Shou et al., "Protecting healthcare professionals during the COVID-19 pandemic," BioMed Research International, vol. 2020, Article ID 8469560, 8 pages, 2020. 